\title{
Inventory Control Application on Indonesia Small Medium Enterprises Using Smartphone
}

\section{Andreas Handojo", Michael Christian Wibisono1, Agustinus Noertjahyana", and Tanti Octavia ${ }^{2}$}

${ }^{1}$ Informatics Engineering, Faculty of Industrial Technology, Petra Christian University, Jl. Siwalankerto 121-131, Surabaya, East Java, Indonesia

${ }^{2}$ Industrial Engineering Department, Faculty of Industrial Technology, Petra Christian University JI. Siwalankerto 121-131, Surabaya, East Java, Indonesia

\section{Abstract}

Small Medium Enterprises (SMEs) playing a big role in domestic economic activities, especially in a developing country such as Indonesia. They accommodate a large amount of employment and generate quite large income for many economic sectors such as textile, furniture, footwear, food and beverages. Usually, SMEs do not have a big stock of goods, consider the SMEs has a low capital. That makes SMEs usually rely on turnover from stock items with a small stock of goods. This certainly causes the

Corresponding Author:

Andreas Handojo

handojo@petra.ac.id

Received: 16 February 2020

Accepted: 5 March 2020

Published: 10 March 2020

Publishing services provided by

Knowledge

(c) Andreas Handojo et al. This article is distributed under the terms of the Creative Commons

Attribution License, which

permits unrestricted use and

redistribution provided that the

original author and source are credited.

Selection and Peer-review under the responsibility of the ICLBI (2018) Conference Committee. monitoring process of the goods of stock's data is very important. If an error occurs, stock-outs can easily arise which can cause loss of sales. Calculation and adjustment of the stock of goods and assets owned by the SME whether in the warehouse or storefront must often be carried out more often. To help inventory control process on SMEs, this research attempt to build a simple inventory control process application. This IT application is expected can operate easily by people who are not familiar with IT and relatively cheap so can be used by various layers of SMEs. The application will be running on Android-based smartphone. The application could download the SMEs stock data and doing inventory control by scanned the barcode that attaches on the item. The scanning process is simply using a camera on the smartphone. After inventory control process, SMEs employee could upload their data directly to a database server using WiFi without re-entry their inventory control result. So this could save employee work time.

Keywords: Android-based application; inventory control process; stock out.

\section{Introduction}

The growth of Small Medium Enterprises (SMEs) is very rapid, especially in developing countries. This is driven by factors that SMEs have an easy permit, easy operational process, only requiring relatively small capital. In Indonesia, SMEs are growing rapidly with a total business unit reaching $99.99 \%$ of all business units in Indonesia [1]. This makes SMEs become a business sector that plays a big role in supporting the country's economy. In addition, SMEs are also able to accommodate $97.24 \%$ of the workforce 
of the total workforce in Indonesia [2]. Therefore, SMEs get special attention from the Indonesian government.

Indonesia government in long-term planned to improve and promote small and medium enterprises (SMEs) by increasing access to capital and implement policies to provide priorities for small and medium entrepreneurs to ensure their competitiveness and sustainability. In terms of competitiveness and sustainability, in general, SMEs have weaknesses in the availability of stock of goods and the number of employees. The stock of goods available generally not too big considering the SMEs has a low capital. Generally, SMEs rely on turnover from stock items with a small stock of goods. SMEs also usually have only a small number of employees (around 5 up to 100).

This certainly causes the process of monitoring the data of goods stock is very important. If an error occurs, stock-outs can easily arise which can cause loss of sales. Calculation and adjustment of the stock of goods and assets owned by the SME whether in the warehouse or storefront must often be carried out more often. The inventory control on stock of goods is carried out to check the difference between the number of goods in the warehouse and the amount recorded. While asset control is to control assets owned by the company, such as furniture, computers, equipment and company equipment.

Inventory control activities on SMEs companies can take a long time depending on the number of goods and assets owned by the company. To facilitate the inventory control process, the process is generally carried out when there are no transactions or not in crowded conditions. This causes the existing inventory data to be less accurate and if there are problems such as missing/damaged items that cannot be known quickly. Another problem is the possibility of recording errors that are carried out if the items recorded are quite large, where employees who make records are required to be able to recognize each item.

Based on these problems, it requires a system that can facilitate the process of inventory and asset control so that the process can be carried out quickly without consuming a lot of time and can provide up-to-date information such as the number of items and the location of goods. This study tried to make a prototype application on an Android-based mobile device to record inventory control by using barcodes that are generally attached to the item. The inventory control process will utilize the camera facilities on the smartphone to read barcodes on items.

The application will then check the data of the items that have been downloaded previously to the smartphone so that employees do not need to remember all the items in the company. Data of goods downloaded from the server consists of the item code, 
item name, amount, location of the goods so that the inventory control process can be done online or offline. After completing the inventory/asset control process, the data obtained can be uploaded to the server so that employees do not need to process inventory control results. The download and upload process could be done via Wi-Fi to connect to the company's computer server.

With this application, it is expected that the inventory control process can be done quickly and easily because it is only by using a smartphone so that it can be carried anywhere, light, and relatively cheap. The application also does not require other devices such as barcode readers. So it's very easy and inexpensive to use. This is considered suitable for users who are small and medium enterprises. With this application, it is expected that the use of information technology in SMEs companies is easy enough to be operated by SMEs employees. Since generally, employees of SMEs are not familiar with high technology.

\section{Problem statement}

Small and Medium Enterprises (SMEs) in Indonesia have a special place in Indonesia's economy. As a developing country, the economy in Indonesia has a special uniqueness where the number of business units of SMEs is $99.99 \%$ of the total existing business units. With the following details, Micro Enterprises (98.74 \%), Small Enterprises (1.15\%), and Medium Enterprises (0.1\%) [1]. It is not much different from the 2012 SMEs data so it can be concluded that the number of SMEs in Indonesia has not changed over the past few years. In terms of labour absorption, SMEs are able to absorb labour by $97.16 \%$ of the total number of workers in Indonesia. With the following details, Micro Enterprises (90.12 \%), Small Enterprises (4.09\%), and Medium Enterprises (2.94 \%) [2]. It can be concluded that SMEs in Indonesia has a very important role in supporting the country's economy.

The Indonesian government has decided that Indonesian SMEs need support for alignment policies especially in response to changing markets and a dynamic economy. The government is also carrying out concrete actions by providing advisory consultants including Production, Financing, Marketing, Human Resources (HR), IT Development, and Development of Cooperation Business Networks. In order to deal with future changes, the Minister of Cooperatives and small and medium enterprises has also conveyed at the APEC SMEWG meeting (September 2016, Lima, Peru) that SME requires increased use of information technology such as computers and smartphones so that SMEs in Indonesia can compete in global markets [3]. 
The use of information technology in Indonesia is very possible. This can be seen from Indonesian internet users that grew to 143260000 people (54.68 \% of the total population). In Indonesia, the smartphone's ownership is up to $50.08 \%$ of the total population [4], which indicates that the online business market should continue to grow. This opportunity is still wide open to any SMEs for improving their business. Indonesia SME information technology (IT) service consumption only USD 278 with only $13.4 \%$ SMEs using IT services on production and $24 \%$ for marketing [5].

Several studies on factors that influence the implementation of IT in SMEs have been carried out such as [5--7]. All existing research concludes that in the development of IT in SMEs, a simple IT system is needed and can be used easily by people who do not really understand IT. In addition, the system created must use technology that is relatively inexpensive so that it can be utilized without the need for the large fund.

Based on this reason, in this study, an inventory and asset control system that was created would use an Android-based smartphone owned by many people. The application will also use camera technology available on smartphones to process barcode scanning. This is expected to facilitate the inventory control process carried out by employees of SMEs. The barcode scan process will use the open-source multi-format $1 D / 2 D$ barcode image processing library that is implemented in Java, namely ZXing (zebra crossing) [8]. ZXing will use the built-in camera on the cellphone to scan and decode barcodes on the device, without having to communicate with the server.

As a media for storing goods data on smartphones, the application will use the SQLite library which is a relational database management system that is ACID-compliant and has a relatively small library code size [9]. So it does not require large storage on a smartphone. This is a consideration so that companies do not need to provide smartphones with a large capacity that is relatively expensive. For data transfer, the application will use JSON web services technology (JavaScript Object Notation) is a lightweight text-based data interchange format [10]. This will make it easier for JSON to read, write and send. Therefore, the data sent will be small and it does not require large data bandwidth.

\section{Research question}

Research question that is trying to answer on this research is how to build an IT application for SMEs to help inventory control process. This IT application is expected can be operated easily by people who are not familiar with IT and relatively cheap so can be used by various layers of SMEs. 


\section{Purpose of the study}

The purpose of this research is to create an IT application that can support the performance of business processes that exist in SMEs, especially in terms of inventory control process that carried out by SMEs employee. The employee can download data on existing items using smartphone Wi-Fi. This data is including item ID, item names, quantities, and location from the item. The employee just scans the barcode attached to the item. The application will do search process for the intended item, then the employee can match the number of items available with the number of items in the system. This inventory control process can also be carried out on more than one warehouse/storage area and used by more than one employee to crosscheck the inventory control data. After completing inventory control, employee just needs to upload the data to the company database (using $\mathrm{Wi}-\mathrm{Fi}$ ) so that they no longer need to enter inventory control data again, so this can save employee work time.

\section{Conceptual models}

This inventory control application will consist of applications on the web server and Android. Figure 1 shows the Use Case Diagram of the application created. The program requires a login from the user first before being able to access available features, such as a view of goods and assets, downloading of goods and assets, and conducting an inventory control process.

System administrators can assign employees to SMEs to carry out an inventory control process in multiple warehouses/storage locations. Data of goods downloaded by each employee is only data of goods that are in the warehouse/storage location where the employee is assigned. Employees can be assigned to one or more warehouses/storage locations and at one warehouse/storage location can be assigned one/more employees. Therefore, this can be used to cross-check data on the inventory control process. When the user will do inventory control process, the smartphone will send user code and commands to retrieve inventory data to the server. Then the server provides inventory control code along with data of goods or assets according to the access rights owned by the user in the form of JSON. On a smartphone, this JSON data is then decoded and then stored on the database on the smartphone.

After that, users can carry out inventory control activities until they are finished. When finished, the user can send their inventory control results to the server computer using the application. The application will send the inventory control process code and the 


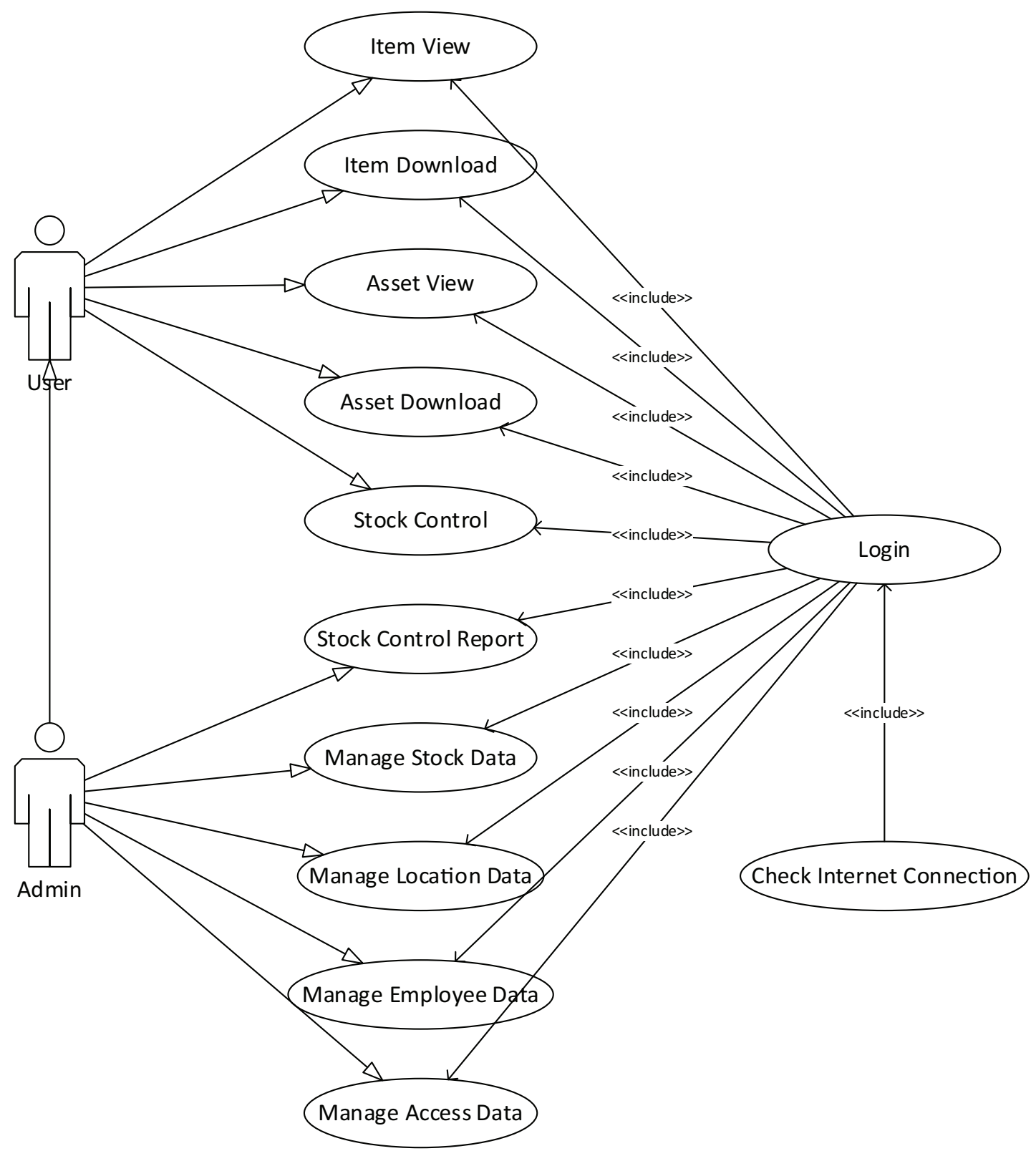

Figure 1: Use case diagram

results of recording data items in the form of JSON. The server then stores the data in accordance with the inventory control process code provided. After success, the smartphone will delete inventory control process data contained on the smartphone, and then display a successful message. In this way, employees do not need to re-enter data on the server so that it can save employee work time.

The design of the Entity Relationship Diagram of the system can be seen in Figure 2. The tables used in this system include employee tables, access rights, location, assets, asset details, items, item details, stock control, stockset details, and stock details. 


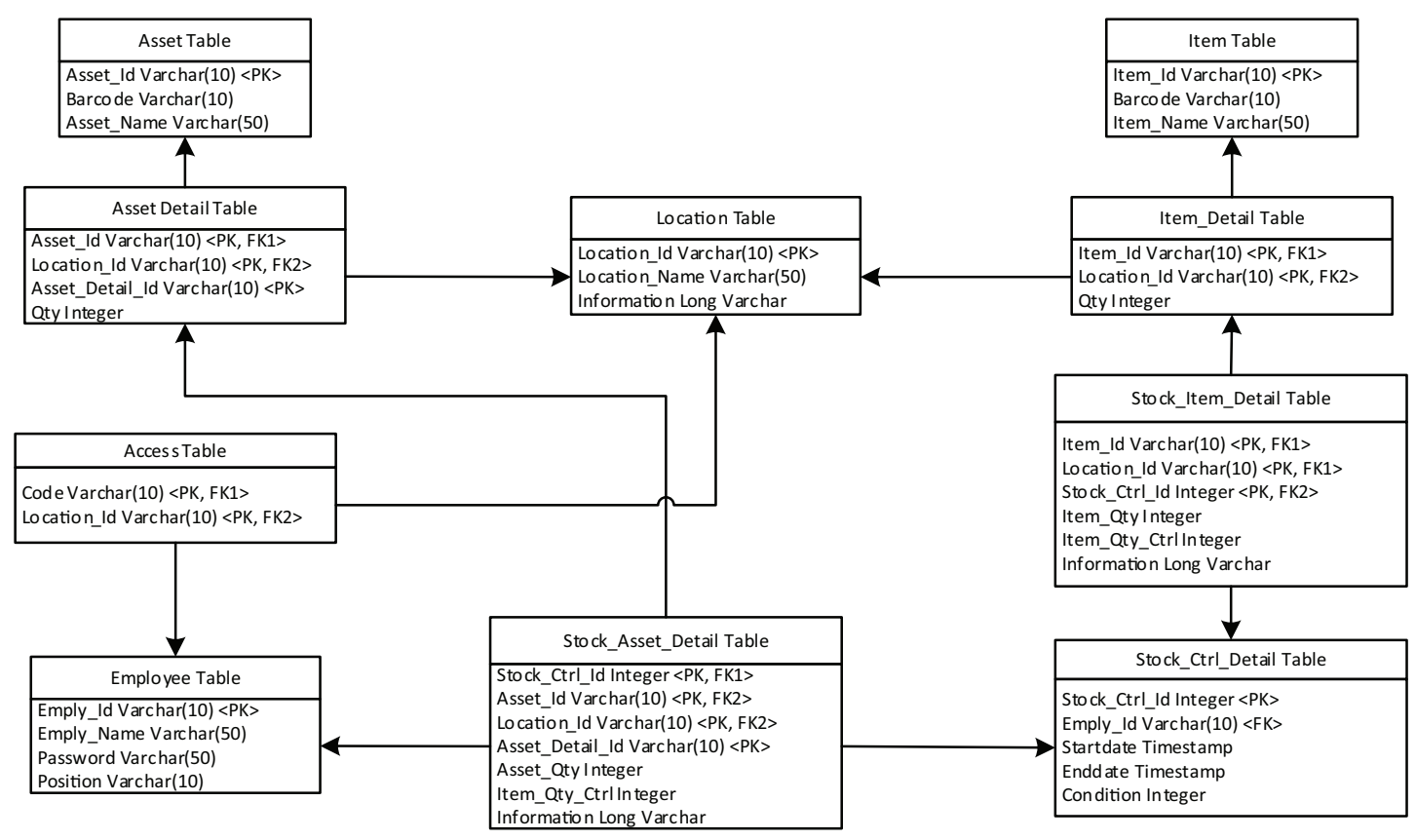

Figure 2: Entity relationship diagram-physical data model

\section{Research methods}

Research method from this research can be described below:

1. Survey of requirement of related SMEs, especially on SMEs that have stocks such as production and retail SMEs.

2. Perform system design as needed.

3. Apply the implementation according to the system design that has been made.

4. Test the applications and systems that have been made on several SMEs.

5. Draw conclusions from research results.

\section{Findings}

Figure 3 shows the appearance of the inventory control application that has been made on the smartphone. After running the application, the user will be asked to log into the system. Users are asked to enter the employee code and password to access the program, and then the smartphone will connect to the server to authorize employee codes and passwords.

If needed, the user can enter the IP address or address of the server to process the data connection (Figure 4). This menu is intended so that applications can be used by 


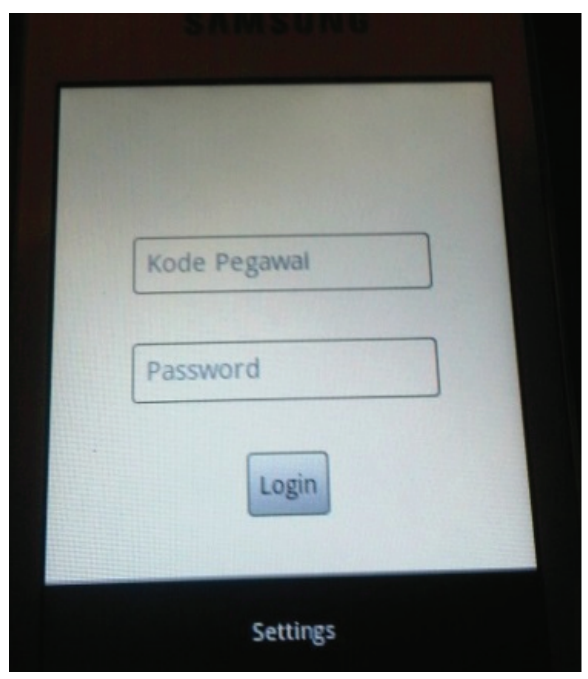

Figure 3: Login menu

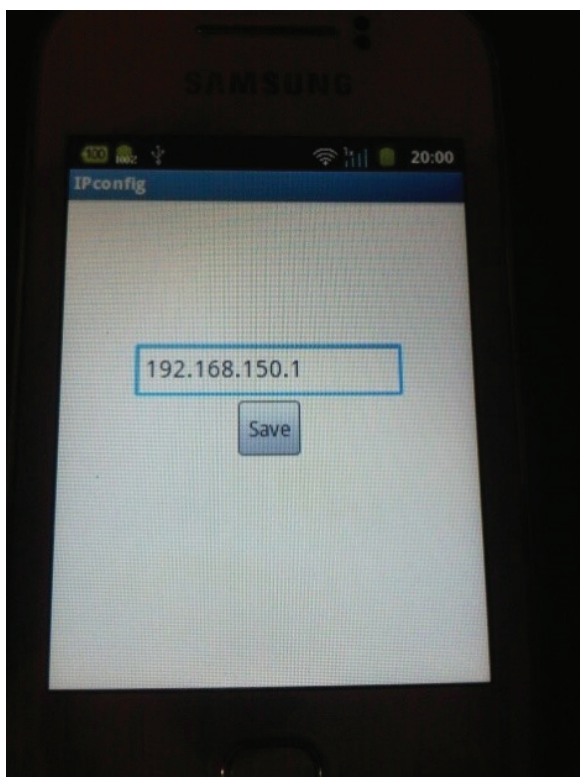

Figure 4: Form setting

each SMEs as needed. In addition, this setting process will allow SMEs to make changes when needed.

After logging in, the application will display the main menu (Figure 5). In the main menu, there are three features, namely item data, asset data, and inventory control.

Users can do the inventory control process by displaying a list of items that must be checked. The appearance of each smartphone can differ depending on the screen width of each smartphone (Figure 6). To enter item data, the user can enter the item code or by scanning the barcode attached to the item (Figures 7 and Figure 8).

Applications sometimes experience problems in obtaining item data when the barcode is skewed (Figure 9). So, the barcode must be scanned upright. 


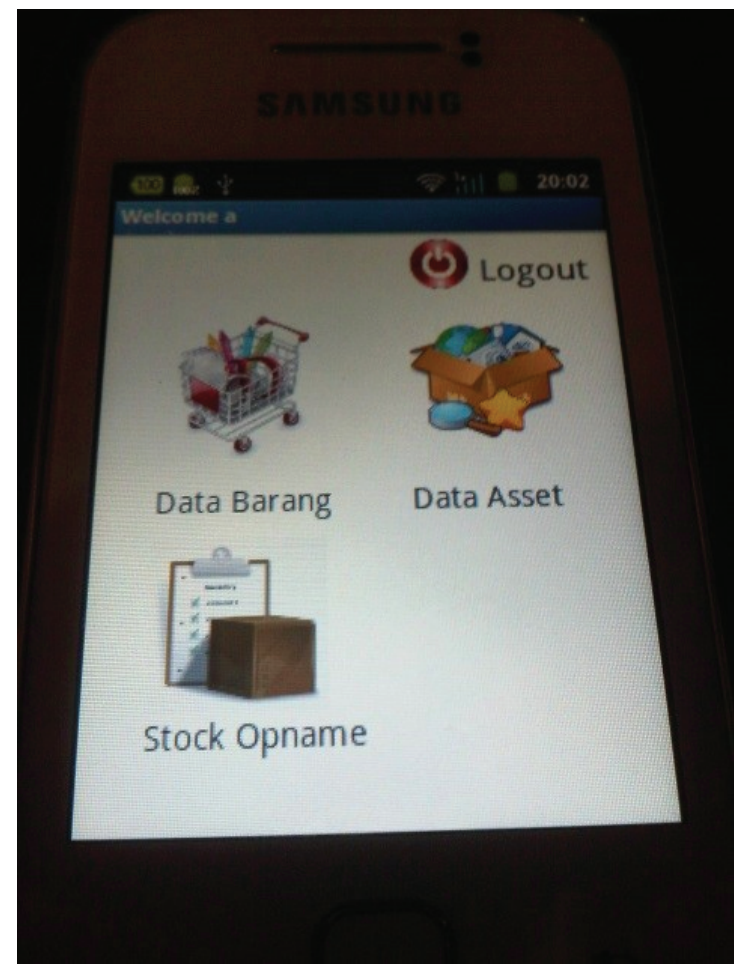

Figure 5: Form main menu

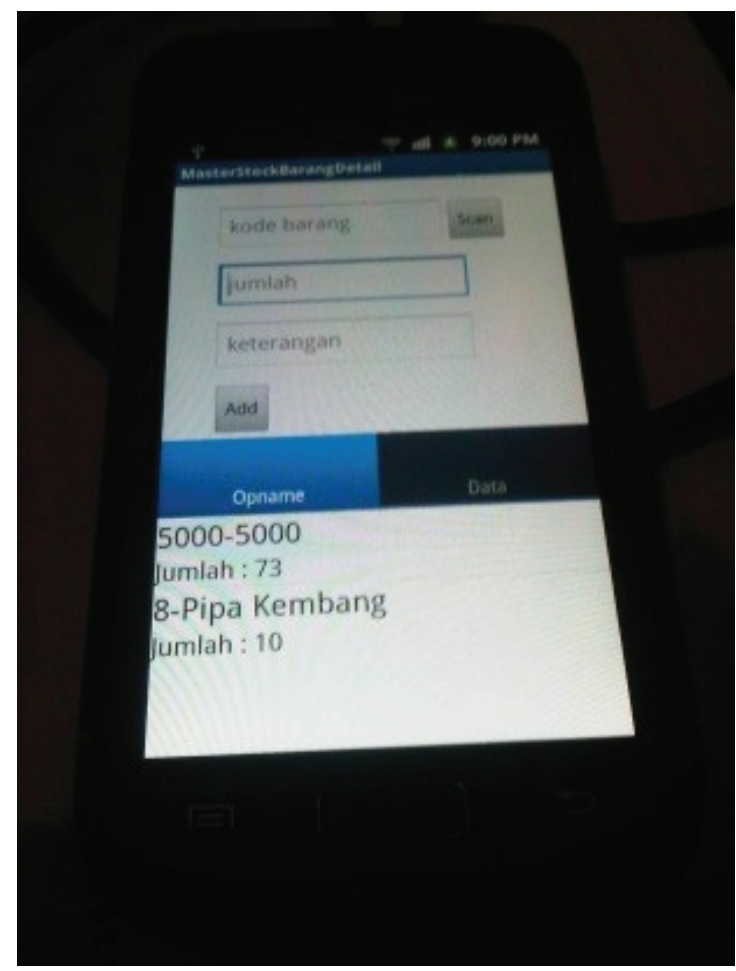

Figure 6: Inventory control process

Goods data along with barcode codes can be entered into the server by the administrator through a website-based application as can be seen in Figure 10 and Figure 11. 


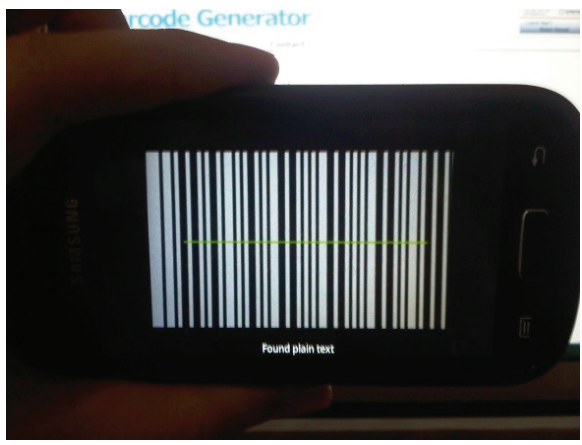

Figure 7: Scan testing on barcode UPC-A

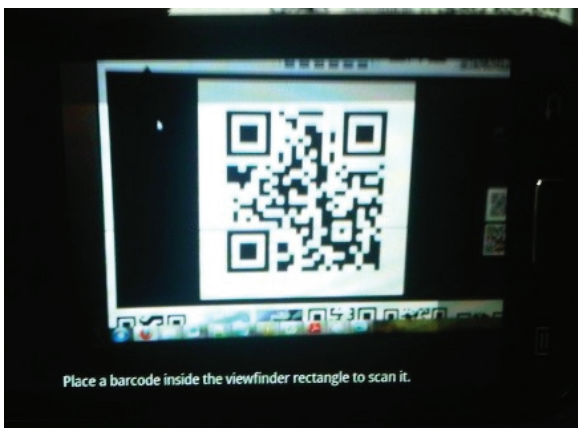

Figure 8: Scan testing on QR Code

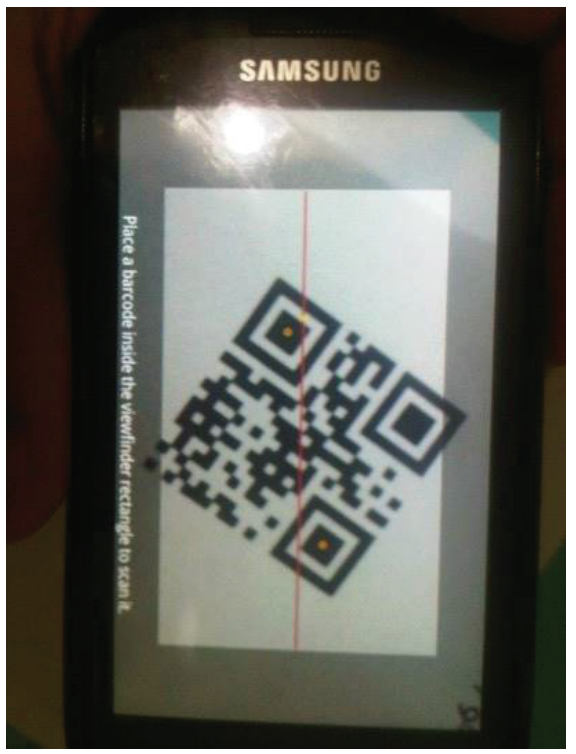

Figure 9: Scan testing on skewed QR code

The results of the inventory control process performed can be seen on the server computer website (Figure 12). These inventory controls results can also be transferred in excel form when needed to simplify the data processing process required by each SMEs (Figure 13). 


\section{ITEM}

\section{Add Item}

\begin{tabular}{|c|c|c|c|c|c|c|}
\hline Item ID & Item Name & Barcode & & & Tools & \\
\hline 1000 & 1000 & 1000 & View & Edit & Stock & Delete \\
\hline 1100 & 1100 & 1100 & View & Edit & Stock & Delete \\
\hline 1234 & 1234 & 1234 & View & Edit & Stock & Delete \\
\hline 5000 & 5000 & 5000 & View & Edit & Stock & Delete \\
\hline 6 & 6 & 6 & View & Edit & Stock & Delete \\
\hline 7 & 6 & 7 & View & Edit & Stock & Delete \\
\hline 8 & 8 & 8 & View & Edit & Stock & Delete \\
\hline$X X X X$ & AAA & BBBB & View & Edit & Stock & Delete \\
\hline
\end{tabular}

Figure 10: Form item

\section{ITEM}

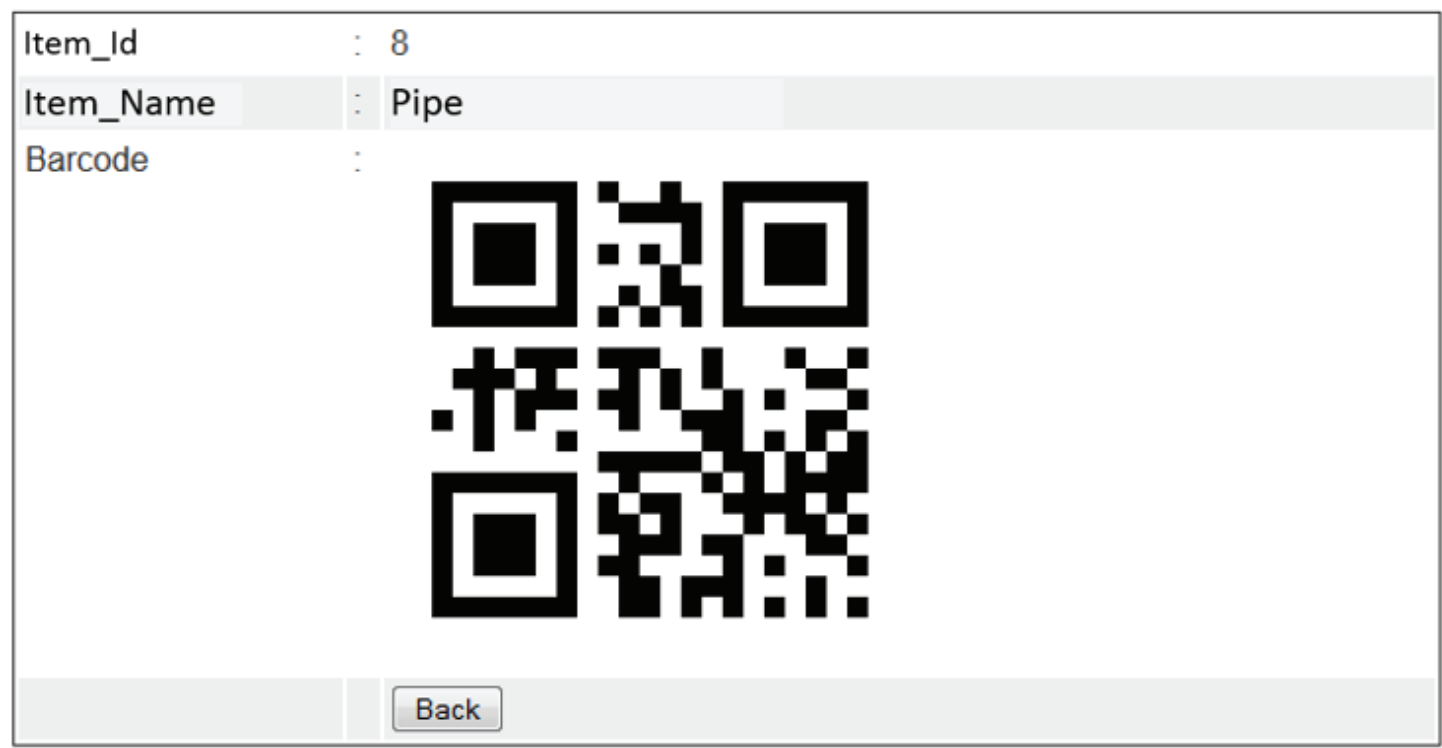

Figure 11: Form barcode entry

\section{Conclusion}

Based on the results of testing that carried out on the application, it can be concluded that the application has been able to download and upload stock items and assets data from the server depending on the authorization of each user. The application also has been able to scan barcodes using a camera smartphone. While scanning process, the barcode position must be scanned upright, if in a certain skewed position the scanning process could be failed to read the barcode. From testing the application to several 


\section{Stock Opname}

\begin{tabular}{|c|c|c|c|c|c|c|c|}
\hline ID Code & $\underset{\text { ID }}{\text { Employee }}$ & Employees Name & Start Date & End Date & Statu & us & Tools \\
\hline 1 & $a$ & a & $2013-04-2504: 56: 23$ & $0000-00-0000: 00: 00$ & Belum Finish & & \\
\hline 2 & a & a & 2013-05-02 07:18:22 & 0000-00-00 00:00:00 & Belum Finish & & \\
\hline 3 & a & a & 2013-05-02 07:18:31 & $0000-00-0000: 00: 00$ & Belum Finish & & \\
\hline 4 & a & a & $2013-05-0207: 34: 38$ & $0000-00-0000: 00: 00$ & Belum Finish & & \\
\hline 5 & a & a & 2013-05-02 08:30:57 & $0000-00-0000: 00: 00$ & Belum Finish & & \\
\hline 6 & a & a & 2013-05-02 08:38:35 & $0000-00-0000: 00: 00$ & Belum Finish & & \\
\hline 7 & a & a & 2013-05-02 08:55:29 & $2013-05-1607: 02: 53$ & Finish & Detail & \\
\hline 8 & a & a & 2013-05-09 07:09:27 & $0000-00-0000: 00: 00$ & Belum Finish & & \\
\hline 9 & a & a & 2013-05-09 07:13:40 & 2013-05-09 09:14:11 & Finish & Detail & \\
\hline 10 & a & a & $2013-05-1607: 03: 28$ & $2013-05-1607: 03: 38$ & Finish & Detail & \\
\hline 11 & a & a & 2013-05-16 07:03:45 & $2013-05-16$ 07:05:25 & Finish & Detail & \\
\hline 12 & a & a & 2013-05-16 07:05:30 & $2013-05-1608: 44: 52$ & Finish & Detail & \\
\hline 13 & a & a & $2013-05-1608: 46: 21$ & $2013-05-1608: 47: 50$ & Finish & Detail & \\
\hline 14 & a & a & 2013-05-16 08:49:07 & $2013-05-1608: 54: 51$ & Finish & Detail & \\
\hline 15 & a & a & $2013-05-1608: 51: 57$ & $2013-05-1608: 52: 13$ & Finish & Detail & \\
\hline 16 & a & a & $2013-05-1608: 52: 29$ & $2013-05-1608: 56: 27$ & Finish & Detail & \\
\hline 17 & a & a & 2013-05-16 09:07:16 & $0000-00-0000: 00: 00$ & Belum Finish & & \\
\hline 18 & a & a & 2013-05-20 07:07:55 & $2013-05-2007: 08: 23$ & Finish & Detail & \\
\hline 19 & admin & admin & $2013-05-20 \quad 07: 09: 54$ & $2013-05-20$ 07:10:55 & Finish & Detail & \\
\hline 20 & admin & admin & $2013-05-2007: 11: 21$ & $2013-05-20 \quad 07: 12: 20$ & Finish & Detail & \\
\hline
\end{tabular}

Figure 12: Form inventory control result

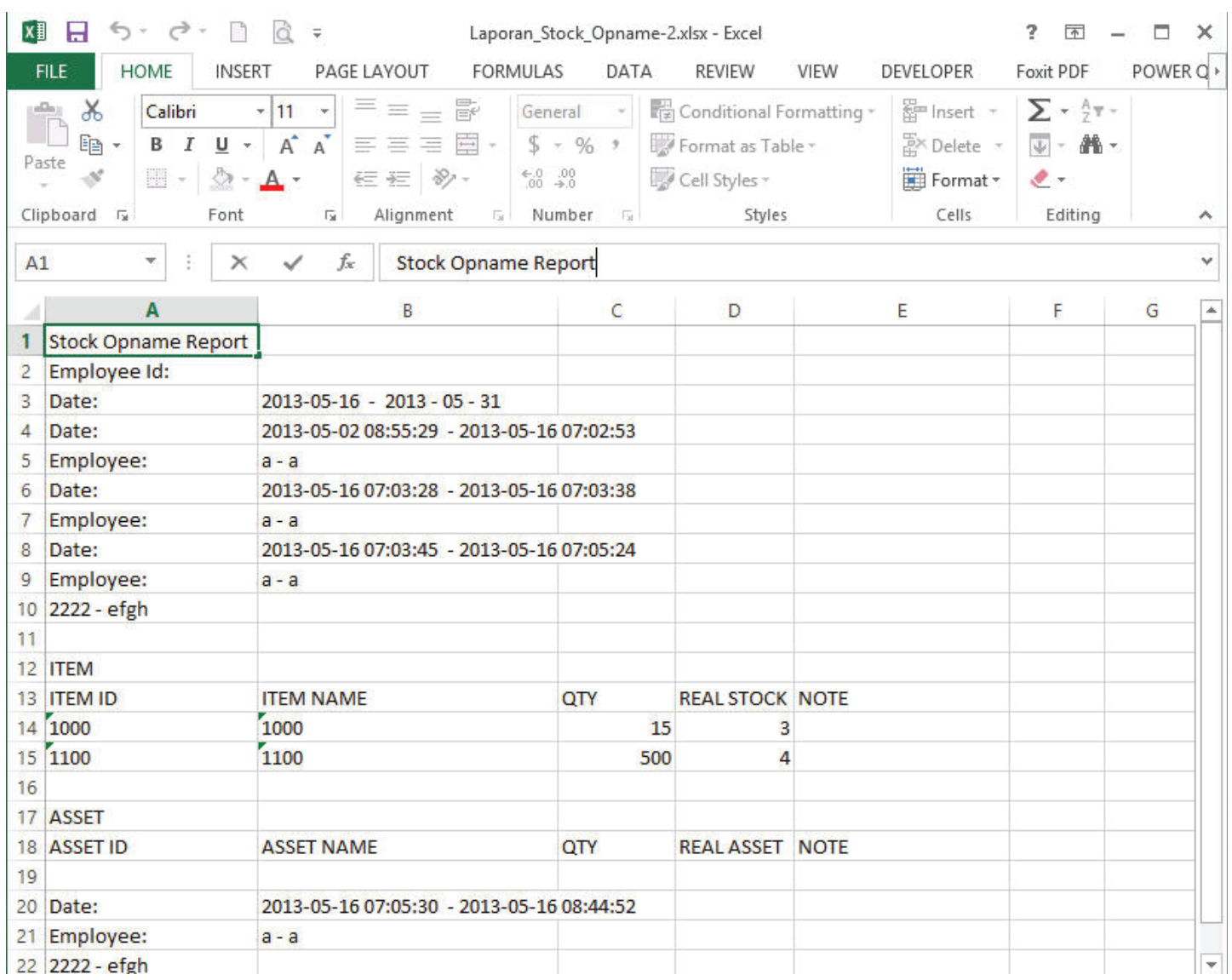

Figure 13: Form inventory control result in Excel

employees on SMEs in various places, results that obtained is that the application was quite easy to use and make the inventory control process quick and easy to conduct.

Some input on application development is the application has not been fully connected to the transaction process on SMEs because the application only utilizes the data items in the database. A complete SMEs application is needed that can also handle sales and purchase transactions, accounting, human resources, etc. 


\section{References}

[1] Kemenkop. Laporan tahunan kementerian KUKM tahun 2016 [Ministry of cooperatives and SMEs year report 2016,Online] from http://www.depkop.go. id/uploads/tx_rtgfiles/Laporan_Tahunan_Kementerian_KUKM_Tahun_2016.pdf (2016). [Accessed on 11 January 2018]. [In Bahasa Indonesia]

[2] Iryanti R.Policy on the development of small, medium and microenterprises and cooperatives in Indonesia [Online] from http://www.ilo.org/wcmsp5/groups/public/ ---asia/---ro-bangkok/---ilo-jakarta/documents/presentation/wcms_559480.pdfl.

(2017). [Accessed on 11 January 2018].

[3] APEC. APEC SMEWG, Lima, Peru [Online] from https://www.apec.org/MeetingPapers/Sectoral-Ministerial-Meetings/Small-and-Medium-Enterprise/2016_sme. aspx (2016). [Accessed on 11 January 2018]

[4] APJII. Indonesia internert usage for business sector [Online] from https://apjii.or. id/downfile/file/SurveiPenggunaanInternetSektorBisnis2013versienglish.pdf (2017). [Accessed on 11 January 2018]

[5] Rachman S, Gregory MA, Narayan SW. The role of ICT services on Indonesian small to medium enterprise productivity. International Telecommunication Networks and Applications Conference 2015; 166--172. https://www.computer.org/csdl/ proceedings-article/itnac/2015/07366807/120mNx5piQk

[6] Jaswadia, Iqbalb M, Sumiadjic. SME governance in Indonesia -- a survey and insight from private companies. Procedia Economics and Finance 2015; 31:387--398. https: //www.sciencedirect.com/science/article/pii/S2212567115012149

[7] Ghobakhloo M, Hong TS, Sabouri MS, Zulkifli N. Strategies for successful information technology adoption in small and medium-sized enterprises. Information 2012; 3:36-67. https://www.mdpi.com/2078-2489/3/1/36/pdf

[8] ZXing. ZXing multi-format 1D/2D barcode image processing library with clients for Android, Java [Online] from code.google.com/p/zxing. (2007). [Accessed on 11 January 2018].

[9] Newman C. SQLite. 1st ed. Sams, United States; 2004. pp. 254--255. https://www. amazon.com/SQLite-Chris-Newman/dp/067232685X

[10] JSON. Introducing JSON [Online] from www.json.org. (2009). [Accessed on 11 January 2018] 